\title{
FREE RADICAL FORMATION IN SALICYLIC ACID AND HEATING PARAMETERS - APPLICATION OF EPR, UV-VIS, TGA AND COLORIMETRY EXAMINATION TO OPTIMIZE THERMAL STERILIZATION
}

\author{
PAWEŁ RAMOS* and BARBARA PILAWA
}

Department of Biophysics, Faculty of Pharmaceutical Sciences in Sosnowiec, Medical University of Silesia, Katowice, 8 Jednosci St., 41-200 Sosnowiec, Poland

\begin{abstract}
Salicylic acid heated at different temperatures and times was examined by an X-band $(9.3 \mathrm{GHz}) \mathrm{EPR}$ spectroscopy, UV-Vis spectrophotometry, TGA and colorimetry test to optimize its thermal sterilization process. Free radical formation $\left(\sim 10^{18} \mathrm{spin} / \mathrm{g}\right)$ during thermal sterilization of salicylic acid according to the pharmaceutical norms at temperature $120^{\circ} \mathrm{C}$ and time of $120 \mathrm{~min}$ were compared with those for heating at the new tested temperatures and times: $130^{\circ} \mathrm{C}$ and $60 \mathrm{~min}$, and $140^{\circ} \mathrm{C}$ and $30 \mathrm{~min}$. It was obtained that the relatively lower free radical concentrations characterized salicylic acid heated at temperatures (times): $120^{\circ} \mathrm{C}(120 \mathrm{~min})$, and $130^{\circ} \mathrm{C}\left(60 \mathrm{~min}\right.$.), than at temperature (time) $140^{\circ} \mathrm{C}(30 \mathrm{~min})$. So treatment at temperature $120^{\circ} \mathrm{C}$ during 120 $\mathrm{min}$, and temperature $130^{\circ} \mathrm{C}$ during $60 \mathrm{~min}$, were recommended as the optimal for thermal sterilization of salicylic acid. Salicylic acid should not be sterilized at temperature $140^{\circ} \mathrm{C}$ for $30 \mathrm{~min}$, because of the highest free radical formation. Free radical systems of thermally treated salicylic acid revealed complex character. Fast spinlattice relaxation processes existed in heated salicylic acid. Strong dipolar interactions characterized all the heated salicylic acid samples. EPR spectroscopy, UV-Vis spectrophotometry, thermogravimetry, and color measurement may be helpful besides microbiological analysis to optimize thermal sterilization conditions of salicylic acid.
\end{abstract}

Keywords: salicylic acid, thermal sterilization, free radicals, EPR spectroscopy, UV-Vis spectrophotometry, thermogravimetry, colorimetry test

Salicylic acid (SA) is an organic compound that belongs to the group of aromaticity alpha hydroxy acids and occurs as a white crystalline powder (1). Oral intake of SA causes gastric ulcers (2-4). For this reason, it is used only externally (2-4). SA is used as a disinfectant and fungicide (2-4). SA at higher concentrations is used as a keratolytic agent (2-4). In the pharmacy formulation salicylic acid is mainly used in the form of solutions and ointments (5-7). SA in the pharmaceutical industry is used as a substrate for the production of acetylsalicylic acid $(1,2)$.

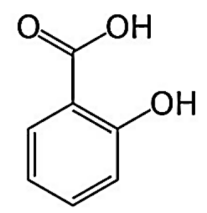

Figure 1. Chemical structure of salicylic acid.
The drugs should be sterile, independent on the way of administration (8-12). Salicylic acid is used in drugs and cosmetics applied on the skin (2-7) so that its sterility seems to be so important. Drugs given to skin diseases should not contain microbes. The sterilization process should be fitted to the type of drug, its stability in the sterilization conditions (812).

Polish (8), European (9) and International (10) Pharmacopoeia, WHO norms (11) and the others norms $(5,6,13,14)$ determine sterilization methods and conditions of thermal sterilization of salicylic acid, but they did not consider the formation of free radicals during heating. In our work, we proposed broadening the tests of sterilization products of salicylic acid from the free radical point of view. Sterile salicylic acid after removing of microorganisms by hot air in sterilizer should not contain high amounts of free radicals. Free radicals concentration and properties were tested by us earlier in other drugs,

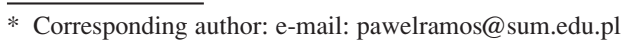


for example: chloramphenicol (15), bismuth subgallate (16), boric acid (17, 18), cefaclor (19), and ursodeoxycholic acid (20). We focused on thermal sterilization, because of economic reasons. The other method of sterilization such as radiative sterilization by gamma irradiation of drugs was connected with the higher costs, and free radicals were also produced in the samples (21-23).

The aim of this work was to characterize free radical properties and concentration formed in salicylic acid during heating at different temperatures and times and to optimize thermal sterilization parameters. The best potential temperatures and times for thermal sterilization of SA were searched by the use of EPR spectroscopy, UV-Vis spectrophotometry, thermogravimetry, and colorimetry methods. The performed studies of products of thermal sterilization of salicylic acid were innovatory. We were heading in the direction of electron paramagnetic resonance (EPR) spectroscopy practical application in the pharmacy during the process of production of drugs.

\section{EXPERIMENTAL}

\section{Samples \\ Salicylic acid}

Salicylic acid of chemical formula $\mathrm{C}_{7} \mathrm{H}_{6} \mathrm{O}_{3}$ was examined. The molecular mass of tested substance is $138.12 \mathrm{~g} / \mathrm{mol}$ (1). The density of SA is 1.440 $\mathrm{g} / \mathrm{cm}^{3}\left(20^{\circ} \mathrm{C}\right)(1)$. Salicylic acid is soluble in ether, carbon tetrachloride, benzene, propanol, acetone, ethanol, methanol, oil of turpentine, toluene, but is weakly soluble in water (1). The tested substance was purchased from Sigma-Aldrich company.

\section{Thermal sterilization - heating parameters}

Salicylic acid was thermally sterilized. The sterilization process was performed in a hot air oven with air circulation, which was the professional apparatus in pharmacy produced by Memmert company (Germany). Recommended norms for thermal sterilization of salicylic acid are temperature $120^{\circ} \mathrm{C}$ and heating time $120 \mathrm{~min}$ (5, 8-10, 13). Additionally, the two other conditions were tested. Salicylic acid was heated at the following temperatures and times: (a) $120^{\circ} \mathrm{C}$ and $120 \mathrm{~min}$ (the proposed by norms), and (b) $130^{\circ} \mathrm{C}$ and $60 \mathrm{~min}$, and (c) $140^{\circ} \mathrm{C}$ and $30 \mathrm{~min}$. The two additional conditions (b, and c) were tested to optimize the thermal sterilization process of salicylic acid. It was checked if the better thermal parameters may be found for salicylic acid sterilization. Temperatures and times resulted in the lowest free radical formation in salicylic acid were considered as the optimal parameters of thermal sterilization. The advanced EPR spectroscopic analysis was done for free radicals in heated salicylic acid. The chemical structure of salicylic acid should remain stable after thermal sterilization. The UV-Vis spectra and color measurement (CIE $\mathrm{L} * \mathrm{a} * \mathrm{~b} *$ color system) of the non-heated and heated salicylic acid gives us the information in this area.

\section{UV-Vis analysis}

UV-Vis spectrophotometer Thermo Genesys 10S produced by Thermo Scientific (Waltham, MA, USA) was used. Methanol solution of salicylic acid in a concentration of $1 \mathrm{mg} / 100 \mathrm{~mL}$ was prepared. The absorption spectra in the wavelength range of $\lambda: 220-$ $400 \mathrm{~nm}$ for the non-heated and heated salicylic acid in methanol solution were obtained. The individual measurement was zeroed on methanol. Methanol was purchased from Sigma-Aldrich company.

\section{Thermogravimetric analysis (TGA)}

The thermal stability of salicylic acid was determined by thermogravimetric analysis. Thermogravimeter TG 209 F3 Tarsus produced by Netzsch (Germany) was used. The thermogravimetric (TG) and derivative thermogravimetric (DTG) thermograms were recorded for $10 \mathrm{mg}$ of salicylic acid at a heating rate of $10 \mathrm{~K} / \mathrm{min}$. in the temperature range of $35-900{ }^{\circ} \mathrm{C}$ under $\mathrm{N}_{2}$ atmosphere. The total nitrogen flow rate was $50 \mathrm{~mL} / \mathrm{min}$. $\mathrm{Al}_{2} \mathrm{O}_{3}$ crucible type use for measured.

\section{Color measurements}

Color measurement in the CIE L*a*b* color system was used as the research techniques. NH 310 colorimeter produced by $3 \mathrm{nh}$ (China) was used. Analyses of color values were done $10 \mathrm{~min}$ after the heating process. The results were compared with the unheated salicylic acid. Measurements collected three times for each sample. The received values were averaged.

The parameters lightness $\left(\mathrm{L}^{*}\right)$, redness $\left(\mathrm{a}^{*}\right)$, and yellowness $\left(b^{*}\right)$, were used to study changes in the color. $\mathrm{L}^{*}$ refers to the lightness of the samples and ranges from black (0) to white (100). A negative value of $a^{*}$ indicates green, while $a^{*}$ positive one indicates red color. Positive $b^{*}$ indicates yellow and negative $b^{*}$ indicates blue color $(24,25)$.

\section{EPR measurements \\ Preparation of the samples to the EPR spectra detection \\ The solid-state salicylic acid samples were put} into thin-walled glass tubes, especially to EPR 
measurements. For the quantitative analysis, salicylic acid samples were weighted. Mass of the individual sample was obtained as the difference between the mass of the tube containing sample and mass of the empty tube. The analytical weight of the CPA Series Sartorius company (Gottingen, Germany) was used.

The glass tubes had high paramagnetic purity. EPR signals were not observed for them at the experimental conditions. The external diameter of the glass tubes was $3 \mathrm{~mm}$.

\section{Parameters and conditions for recorded EPR spectra}

EPR spectra for salicylic acid samples were measured at room temperature $15 \mathrm{~min}$ after thermal sterilization by the use of electron paramagnetic resonance spectrometer of Radiopan company (Poznań, Poland). The microwaves were from the X-band with a frequency of $9.3 \mathrm{GHz}$. The microwave frequency was measured by the MCM101 recorder produced by the EPRAD company (Poznań, Poland). The magnetic modulation was $100 \mathrm{kHz}$. Microwave power was in the range from $2.2 \mathrm{~mW}$ to the total microwave power produced by klystron of $70 \mathrm{~mW}$. The attenuations corresponding to these microwave powers were $15 \mathrm{~dB}-0 \mathrm{~dB}$. Numerical acquisition of the EPR spectra was performed by the Rapid Scan Unit produced by Jagmar (Kraków, Poland). The EPR spectra were measured as the first-derivative lines.
EPR spectra were measured and analyzed by the use of professional spectroscopic programs of Jagmar company (Kraków, Poland) and LabView of National Instruments company (Austin, TX, USA).

\section{Analyzed parameters of the EPR spectra}

The following parameters were analyzed: g-factors [ \pm 0.0002$]$, amplitudes (A) [ \pm 0.01 a.u.], integral intensities (I) $[ \pm 0.02$ a.u.], and linewidths $\left(\Delta \mathrm{B}_{\mathrm{pp}}\right)[ \pm 0.02 \mathrm{mT}]$ of the EPR spectra. g-Factors were calculated according to the formula $(26,27)$ : $\mathrm{g}=\mathrm{h} v / \mu_{\mathrm{B}} \mathrm{B}_{\mathrm{r}}$, where: $\mathrm{h}-$ Planck constant, $\mathrm{v}-$ microwave frequency, $\mu_{B}-$ Bohr magneton, $B_{r}-$ induction of resonance magnetic field. Integral intensity (I) as the area under the absorption line was obtained by double integration of the first-derivative EPR spectra.

The following shape parameters as the asymmetry parameters: $A_{1}-A_{2}$, and $B_{1}-B_{2}$, were analyzed. Figure 2 shows amplitude $(A)$, linewidth $\left(\Delta B_{p p}\right)$, and the parameters: $A_{1}, A_{2}, B_{1}$, and $B_{2}$. The influence of microwave power on these parameters was determined.

Free radical concentration - formula and determination

Free radical concentration $(\mathrm{N})\left[ \pm 0.2 \times 10^{18}\right.$ spin/g] in the heated salicylic acid samples was determined according to the formula (26-28): $\mathrm{N}=$ $\mathrm{N}_{\mathrm{u}}\left[\left(\mathrm{W}_{\mathrm{u}} \mathrm{A}_{\mathrm{u}}\right) / \mathrm{I}_{\mathrm{u}}\right] \times[\mathrm{I} /(\mathrm{WAm})]$, where: $\mathrm{N}_{\mathrm{u}}$ - number of paramagnetic centers in ultramarine (reference); $\mathrm{W}$,

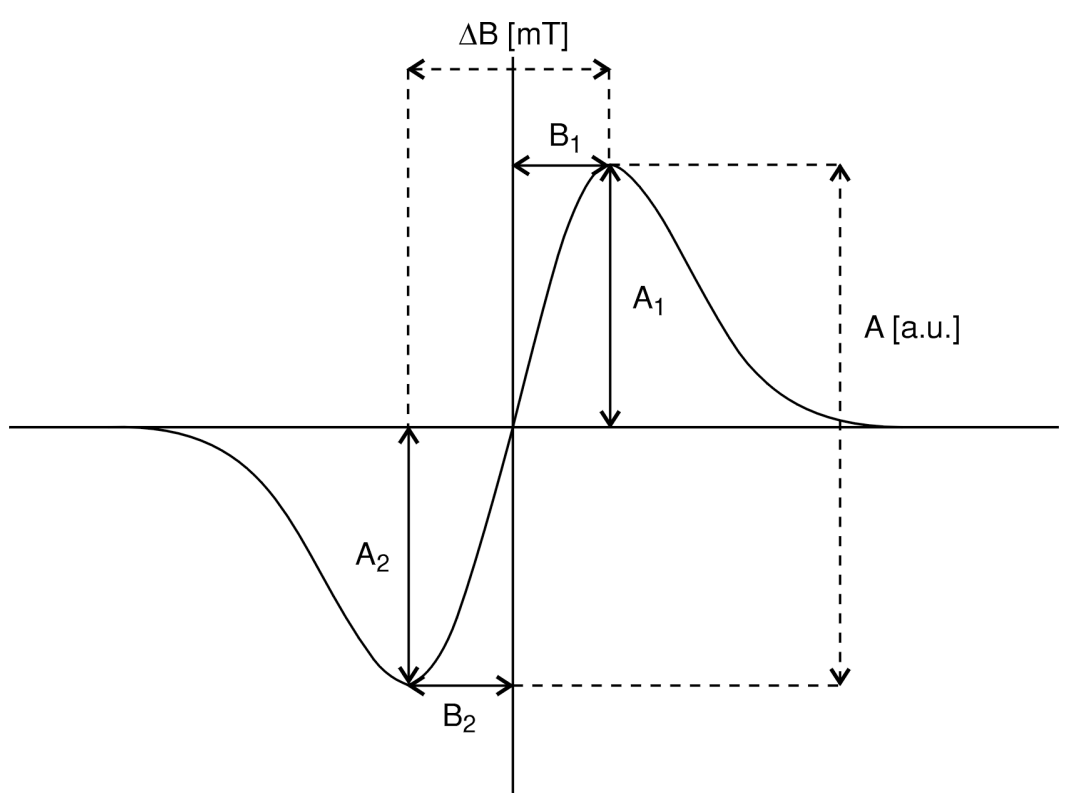

Figure 2. The analyzed parameters of the EPR spectra: amplitude (A), linewidth $\left(\Delta B_{p p}\right)$, and shape parameters: $A_{1}, A_{2}, B_{1}$, and $B_{2}$. 
$\mathrm{W}_{\mathrm{u}}$ - receiver gains for the tested drug samples and ultramarine; $\mathrm{A}, \mathrm{A}_{\mathrm{u}}$ - amplitudes of ruby signal for the tested samples and the ultramarine; $\mathrm{I}, \mathrm{I}_{\mathrm{u}}$ - integral intensities for the tested salicylic acid samples
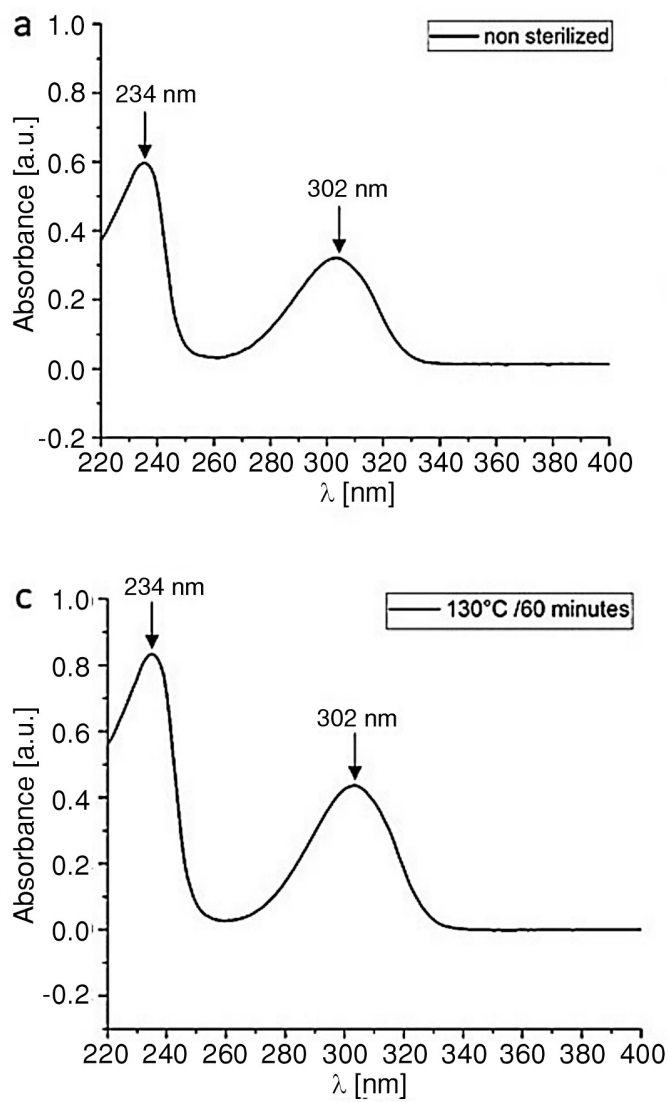

and ultramarine, $\mathrm{m}$ - mass of the salicylic acid sample.

The used reference - ultramarine was paramagnetic stabile and it revealed a strong EPR signal.

Figure 3. UV-Vis spectra of salicylic acid non-heated (a), and heated at temperatures and times: (b) $120^{\circ} \mathrm{C}, 120 \mathrm{~min},(\mathrm{c}) 130^{\circ} \mathrm{C}, 60 \mathrm{~min}$, and $(\mathrm{d}) 140^{\circ} \mathrm{C}, 30 \mathrm{~min}$.
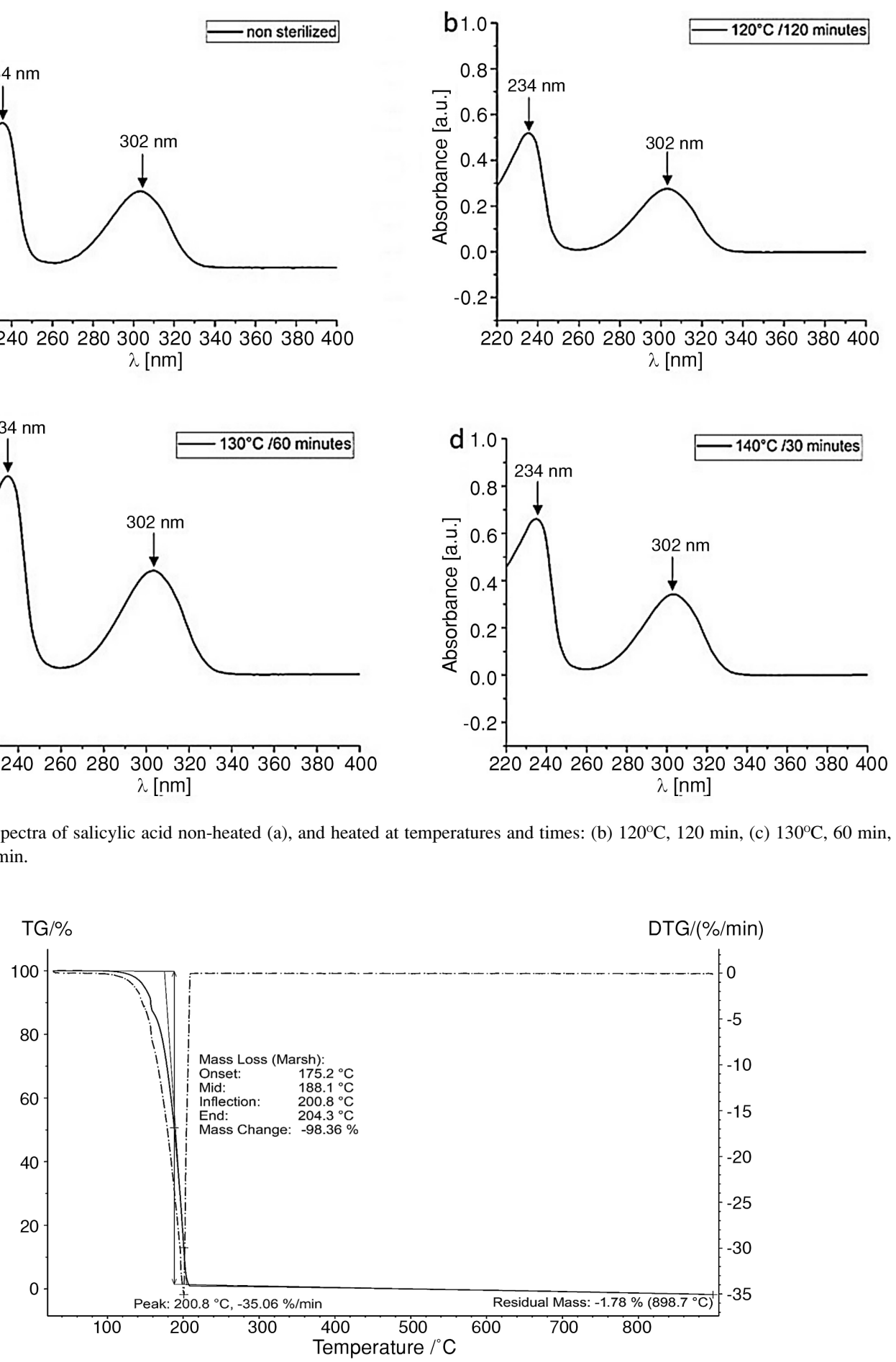

Figure 4. Decomposition of salicylic acid, illustrated by the TG, and DTG curves. 


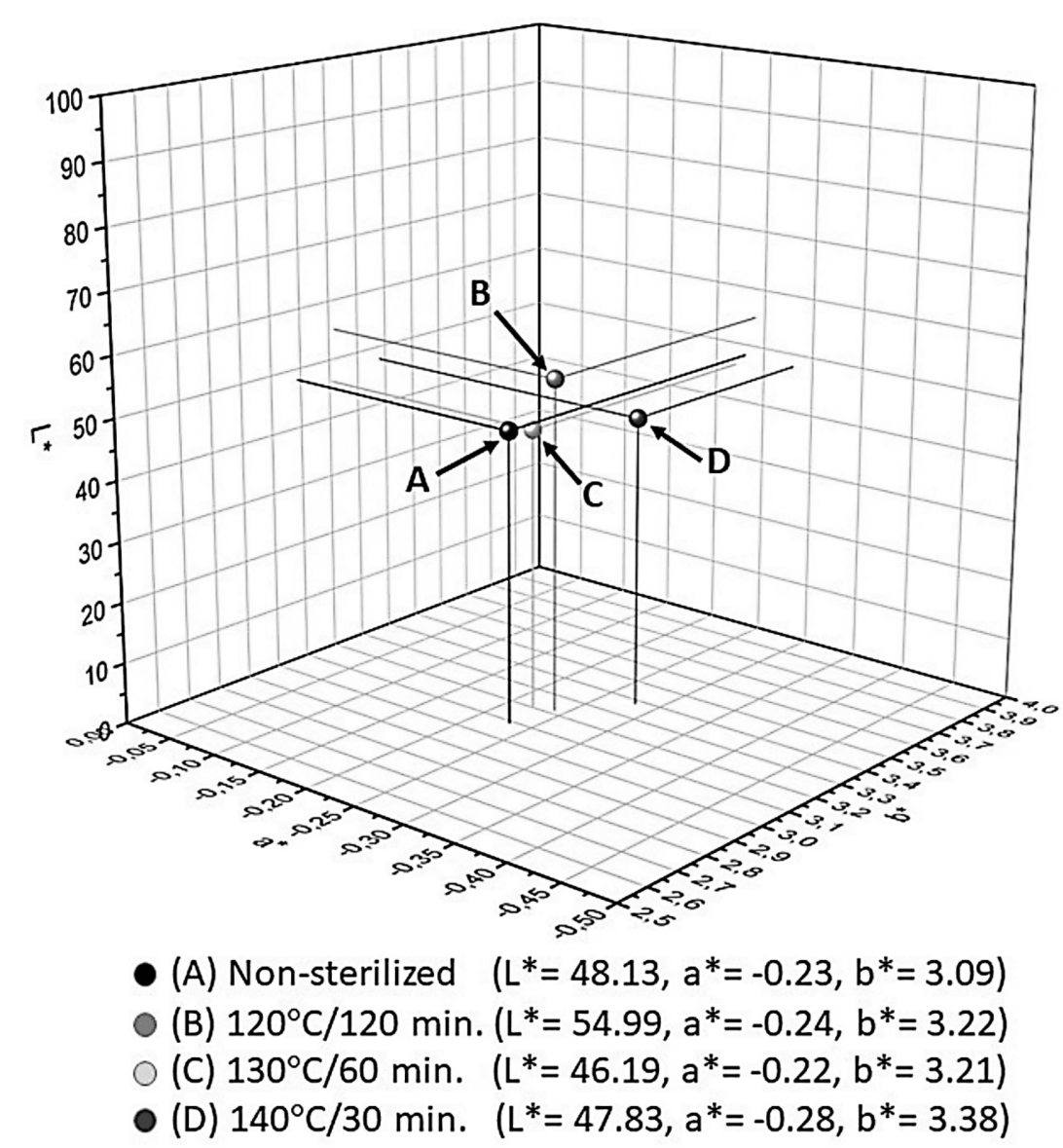

Figure 5. Analysis of color in the 3D (CIE L*a*b*) space for non-sterilized and sterilized salicylic acid.

The second reference, a ruby crystal $\left(\mathrm{Al}_{2} \mathrm{O}_{3}: \mathrm{Cr}^{3+}\right)$ was permanently placed in the resonance cavity below the samples, and its EPR signals were measured when both ultramarine or salicylic acid were located in the cavity.

\section{RESULT AND DISCUSSION}

UV-Vis examination indicated that the used temperatures and times of heating may be acceptable from the point of view of the stability of the chemical structure of salicylic acid. Chemically SA is a 2-hydroxybenzoic acid, contained one hydroxyl group and one carboxyl group in the ortho position $(29,30)$. Salicylic acid has a free phenyl group, which means that the UV spectrum shows the bathochromic shift of the benzenoid band to a wavelength of $302 \mathrm{~nm}$ in methanol (30). Similar UV spectra for salicylic acid in methyl alcohol were recorded at work (31). UV-Vis absorption lines for the original non-treated by higher temperatures salicylic acid and salicylic acid heated at temperatures $120^{\circ} \mathrm{C}$ for $120 \mathrm{~min}, 130^{\circ} \mathrm{C}$ for $60 \mathrm{~min}$, and $140^{\circ} \mathrm{C}$ for $30 \mathrm{~min}$, were shown in Figure $3 \mathrm{a}-\mathrm{d}$. UV-Vis spectra were similar for the non-heated and heated salicylic acid.

Thermogravimetric analysis curves of salicylic acid were shown in Figure 4. There is only one single mass-loss step representing an almost complete decomposition (residual mass of only $1.78 \%$ ). The corresponding 1 st derivative of the TG curve, DTG, provides the decomposition rate. The DTG peak temperature $\left(200.8^{\circ} \mathrm{C}\right)$ is usually used as a characteristic value to specify the appropriate step. The salicylic acid onset the mass lost at $175.2^{\circ} \mathrm{C}$, and end the mass lost at $204.3^{\circ} \mathrm{C}$. The mass change of the decomposition process of salicylic acid was $98.36 \%$. Similar results were obtained at work (32). Lindquist E. and Yang Y. showed the degradation of salicylic acid in water solution at $150^{\circ} \mathrm{C}$ for $30 \mathrm{~min}$ is $5 \%$ (33).

The location of colors in CIE L*a*b* space is illustrated in Figure 6. Axes $L^{*}, a^{*}$ and $b^{*}$ define the 3D color space CIE. So, if coordinates $\mathrm{L}^{*}, \mathrm{a}^{*}$ and $\mathrm{b}^{*}$ 
are known, then the color is described and also located in space. Inside this system, any color can be denoted through coordinates $\mathrm{L}^{*}, \mathrm{a}^{*}$ and $\mathrm{b}^{*}(25)$.

Measurement in the CIE L*a*b* color system has shown that the temperatures and heating times may be acceptable from the point of view of the salicylic acid color change. The CIE L*a*b* parame- ters were similar for the non-heated and heated salicylic acid. Most similarly CIE L*a*b* color parameters for non-heated salicylic acid have salicylic acid heated at $130^{\circ} \mathrm{C}$ for $60 \mathrm{~min}$ (new proposed conditions) (Fig. 5). The most different CIE L*a*b* color parameters for non-heated salicylic acid have salicylic acid heated at $140^{\circ} \mathrm{C}$ for $30 \mathrm{~min}$ (Fig. 5).
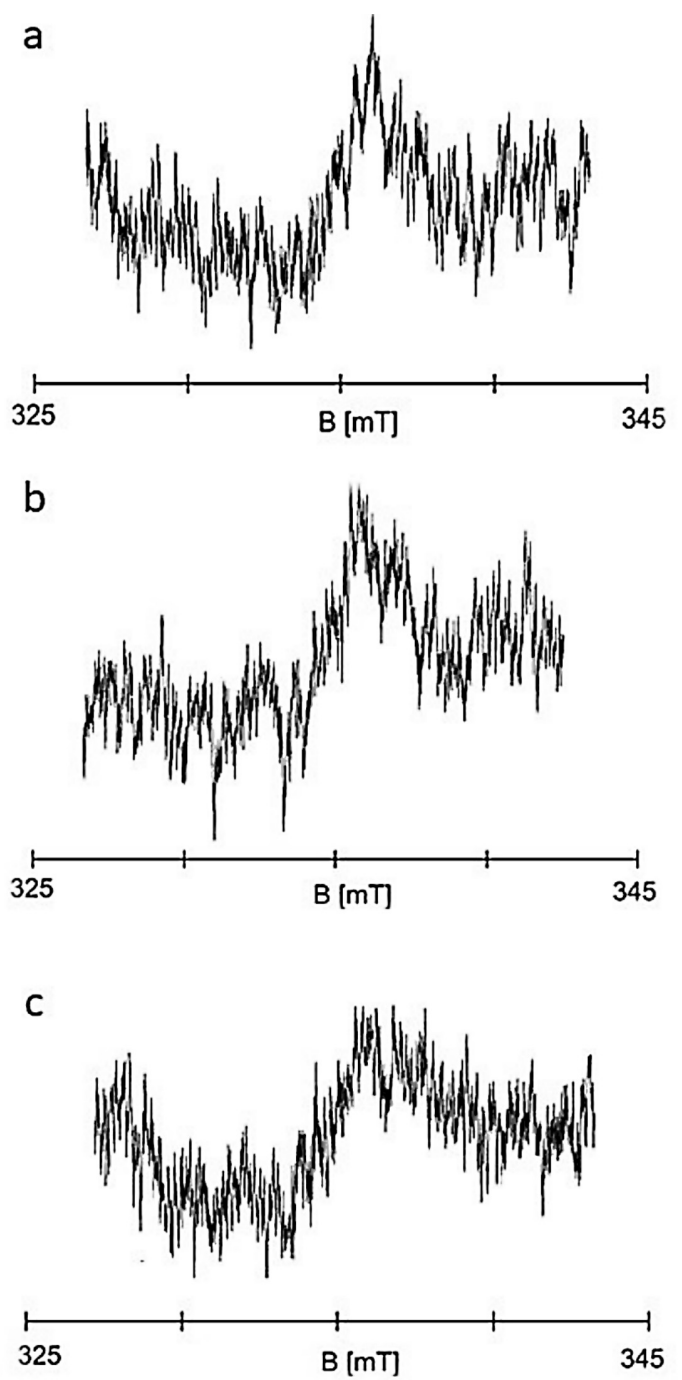

Figure 6. EPR spectra of salicylic acid heated at temperatures and times: (a) $120^{\circ} \mathrm{C}, 120 \mathrm{~min}$, (b) $130^{\circ} \mathrm{C}, 60 \mathrm{~min}$, and (c) $140^{\circ} \mathrm{C}, 30 \mathrm{~min}$. B - magnetic induction. The spectra were measured with a microwave power of $2.2 \mathrm{~mW}$.

Table 1. Parameters of the EPR spectra of salicylic acid heated at different temperatures: amplitudes (A), integral intensities (I), and linewidths $\left(\Delta \mathrm{B}_{\mathrm{pp}}\right) . \mathrm{T}, \mathrm{t}$ - temperature and time of heating, respectively. Data for the EPR spectra measured with a microwave power of 2.2 $\mathrm{mW}$ (attenuation of $15 \mathrm{~dB}$ ) were presented.

\begin{tabular}{|c|c|c|c|c|}
\hline $\begin{array}{c}\mathrm{T} \\
{\left[{ }^{\circ} \mathrm{C}\right]}\end{array}$ & $\begin{array}{c}\mathrm{t} \\
{[\text { minutes }]}\end{array}$ & $\begin{array}{c}\mathrm{A} \\
{[ \pm 0.01 \text { a. u. }]}\end{array}$ & $\begin{array}{c}\mathrm{I} \\
{[ \pm 0.02 \text { a. u. }]}\end{array}$ & $\begin{array}{c}\Delta \mathrm{B}_{\mathrm{pp}} \\
{[ \pm 0.02 \mathrm{mT}]}\end{array}$ \\
\hline $120^{\circ} \mathrm{C}$ & 120 & 0.24 & 1.13 & 0.98 \\
\hline $130^{\circ} \mathrm{C}$ & 60 & 0.18 & 0.81 & 0.84 \\
\hline $140^{\circ} \mathrm{C}$ & 30 & 0.20 & 2.32 & 1.31 \\
\hline
\end{tabular}




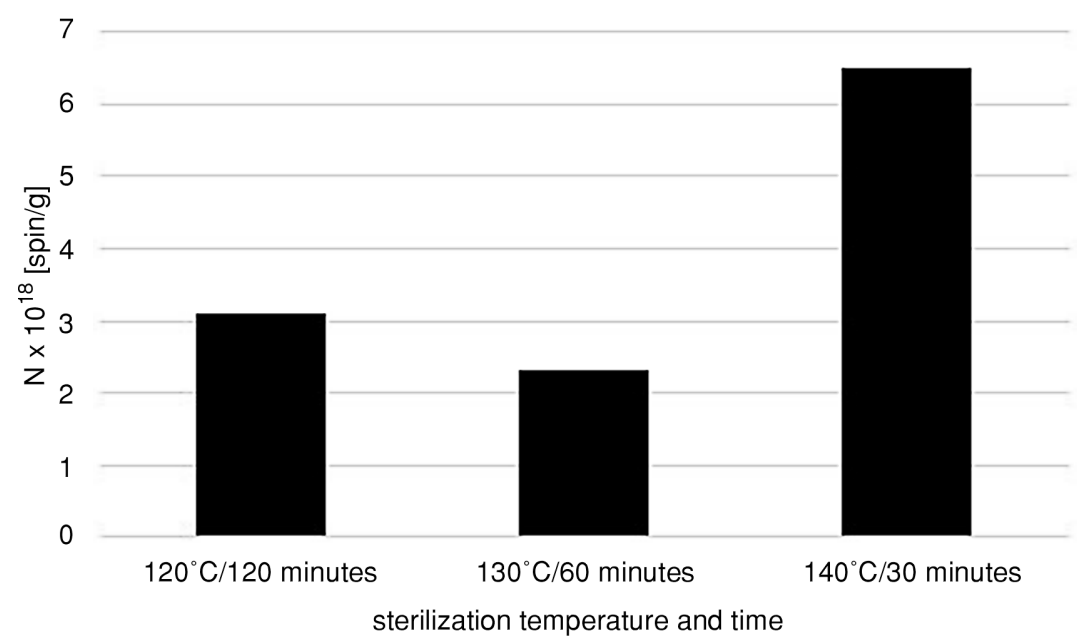

Figure 7. The effect of temperature and time of thermal treatment on free radical concentrations $(\mathrm{N})$ in salicylic acid. Temperatures and times of heating were: (a) $120^{\circ} \mathrm{C}$ and $120 \mathrm{~min}$, (b) $130^{\circ} \mathrm{C}$ and $60 \mathrm{~min}$, and (c) $140^{\circ} \mathrm{C}$ and $30 \mathrm{~min}$.

EPR spectra were not obtained for the nonheated salicylic acid, because of the absence of unpaired electrons in its structure (1). The heating of salicylic acid caused free radical formation in the samples independent of temperature and time. EPR spectra with g-factors near 2 characteristic for free radicals appeared after the thermal treatment of salicylic acid. EPR spectra of salicylic acid heated at temperatures (times): $120^{\circ} \mathrm{C}(120 \mathrm{~min}), 130^{\circ} \mathrm{C}(60$ $\mathrm{min}$ ), and $140^{\circ} \mathrm{C}$ (30 min), were shown in Figure 6 a-c. Parameters of the EPR spectra: amplitudes (A), integral intensities $(\mathrm{I})$, and linewidths $\left(\Delta \mathrm{B}_{\mathrm{pp}}\right)$, were compared in Table 1 . The lower amplitude (A), integral intensity $(\mathrm{I})$, and linewidth $\left(\Delta \mathrm{B}_{\mathrm{pp}}\right)$, revealed EPR spectrum of salicylic acid heated at temperature $130^{\circ} \mathrm{C}$ for $60 \mathrm{~min}$ (Table 1). The highest integral intensity (I) was obtained for salicylic acid heated at temperature $140^{\circ} \mathrm{C}$ for $30 \mathrm{~min}$. All the EPR lines were broad with linewidths $\left(\Delta \mathrm{B}_{\mathrm{pp}}\right)$ in the range 0.84-1.31 mT (Table 1). Strong dipolar interactions between free radicals were responsible for line broadening. The higher dipolar interactions were observed from the highest line broadening for salicylic acid thermally treated at temperature $140^{\circ} \mathrm{C}$ for $30 \mathrm{~min}$. The relatively weakest dipolar interactions existed in salicylic acid heated at temperature $130^{\circ} \mathrm{C}$ during $60 \mathrm{~min}$, because of the relatively lowest linewidths $\left(\Delta \mathrm{B}_{\mathrm{pp}}\right)$. Broad EPR lines were also observed by us for the other heated drugs, for example for chloramphenicol (15) and boric acid (17).

Concentrations of free radicals $(\mathrm{N})$ in the salicylic acid samples depended on temperature and time of heating. Free radical concentrations $(\mathrm{N})$ in salicylic acid thermally treated at temperatures $120^{\circ} \mathrm{C}$ for $120 \mathrm{~min}, 130^{\circ} \mathrm{C}$ for $60 \mathrm{~min}$, and $140^{\circ} \mathrm{C}$ for $30 \mathrm{~min}$, were compared in the diagram in Figure 7. Free radical concentrations $(\mathrm{N})$ in thermally treated salicylic acid were $\sim 10^{18} \mathrm{spin} / \mathrm{g}$. The relatively lower free radical concentrations $(\mathrm{N})$ characterized salicylic acid thermally sterilized according to the pharmaceutical norms at temperature $120^{\circ} \mathrm{C}$ for $120 \mathrm{~min}$ $\left(3.1 \times 10^{18} \mathrm{spin} / \mathrm{g}\right)$, and according to proposed by us new conditions at temperature $130^{\circ} \mathrm{C}$ for $60 \mathrm{~min}(2.3$ $\times 10^{18} \mathrm{spin} / \mathrm{g}$ ). These above two conditions may be used for thermal sterilization of salicylic acid. The highest free radical concentration $(\mathrm{N})$ obtained for salicylic acid thermally treated at temperature $140^{\circ} \mathrm{C}$ for $30 \mathrm{~min}$. The UV-Vis spectra and EPR examination let us recommend the new parameters of thermal sterilization of salicylic acid as a temperature of $130^{\circ} \mathrm{C}$ and time of $60 \mathrm{~min}$. This temperature and time generated the least free radicals in thermally sterilized salicylic acid. The chemical structure was not destroyed at these conditions (Fig. 3) and free radical concentration $(\mathrm{N})$ was the lowest (Fig. 7). The negative result was obtained by us for temperature $140^{\circ} \mathrm{C}$ and heating time $30 \mathrm{~min}$ for thermal sterilization of salicylic acid.

EPR spectra of salicylic acid depended on microwave power used during the measurement. The changes of amplitudes (A) of the EPR spectra of salicylic acid heated at temperatures $120^{\circ} \mathrm{C}$ for 120 $\min , 130^{\circ} \mathrm{C}$ for $60 \mathrm{~min}$, and $140^{\circ} \mathrm{C}$ for $30 \mathrm{~min}$, were presented in Figure 8 a-c, respectively. Amplitudes (A) increased with the increase of microwave power, and the effect of microwave saturation of the EPR lines was not observed. Such correlation was characteristic for fast spin-lattice relaxation process- 
es in the samples (26-28). The similar fastness of spin-lattice relaxation processes in salicylic acid heated at different conditions pointed out that the chemical structure was saved. The changes of linewidths $\left(\Delta \mathrm{B}_{\mathrm{pp}}\right)$ of the EPR spectra of salicylic acid heated at temperatures $120^{\circ} \mathrm{C}$ for $120 \mathrm{~min}$, $130^{\circ} \mathrm{C}$ for $60 \mathrm{~min}$, and $140^{\circ} \mathrm{C}$ for $30 \mathrm{~min}$, were presented in Figure 8 d-f, respectively. The linewidths $\left(\Delta \mathrm{B}_{\mathrm{pp}}\right)$ of the EPR spectra increased with increasing of microwave power for all the heated salicylic acid samples. It was characteristic for homogeneously broadened EPR lines (26-28).

The shape of the EPR spectra of salicylic acid was modified by the increase of microwave power. The influence of microwave power on the shape parameters: $A_{1}-A_{2}$, and $B_{1}-B_{2}$, for the EPR spectra of salicylic acid thermally treated at temperatures $120^{\circ} \mathrm{C}$ during $120 \mathrm{~min}, 130^{\circ} \mathrm{C}$ during $60 \mathrm{~min}$, and $140^{\circ} \mathrm{C}$ during $30 \mathrm{~min}$, were shown in Figure $9 \mathrm{a}-\mathrm{c}$, and e-f respectively. All the tested parameters depended on microwave power and the character of the changes was visible in Figure 9. The changes in spectral shape with microwave power indicated the complex character of the free radical system in the heated salicylic acid. Free radicals with different localization of unpaired electrons existed in the samples. Taking into account its chemical structure (1), it may be said that mainly free radicals with unpaired electrons on carbon $(\mathrm{C})$ and oxygen $(\mathrm{O})$ atoms appeared in salicylic acid during thermal treatment. The complex structure of the free radical system was also observed by us for chloramphenicol (15), cholic acids (20), ampicillin (34), neomycin (35). This effect was probably the result of the thermal rupturing of different chemical bonds in the samples. Reactions with oxygen may be also taken into account.

The results obtained in this work pay attention to the important meaning of examination of thermal sterilization products by major experimental tech-
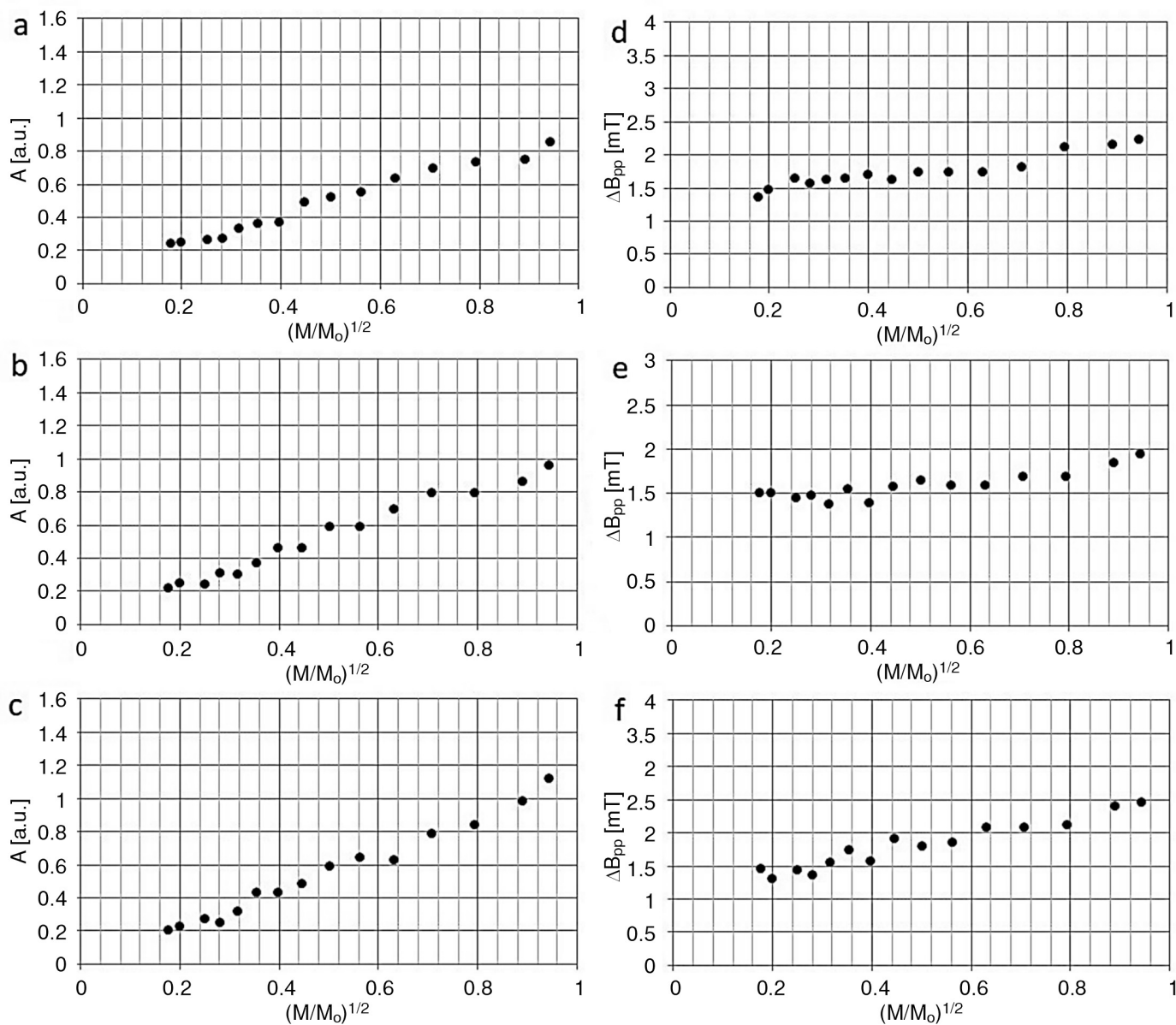

Figure 8. The influence of microwave power $\left(\mathrm{M} / \mathrm{M}_{\mathrm{o}}\right)$ on amplitudes $(\mathrm{A})(\mathrm{a}-\mathrm{c})$ and linewidths $\left(\Delta \mathrm{B}_{\mathrm{pp}}\right)(\mathrm{d}-\mathrm{f})$ of the EPR line of salicylic acid heated at temperatures and times: (a, d) $120^{\circ} \mathrm{C}$ and $120 \mathrm{~min}$, (b, e) $130^{\circ} \mathrm{C}$ and $60 \mathrm{~min}$, and (c, f) $140^{\circ} \mathrm{C}$ and $30 \mathrm{~min} . \mathrm{M}_{\mathrm{o}}, \mathrm{M}-$ the maximal microwave power $(70 \mathrm{~mW})$, and microwave power used during the measurement of the EPR spectra, respectively. 

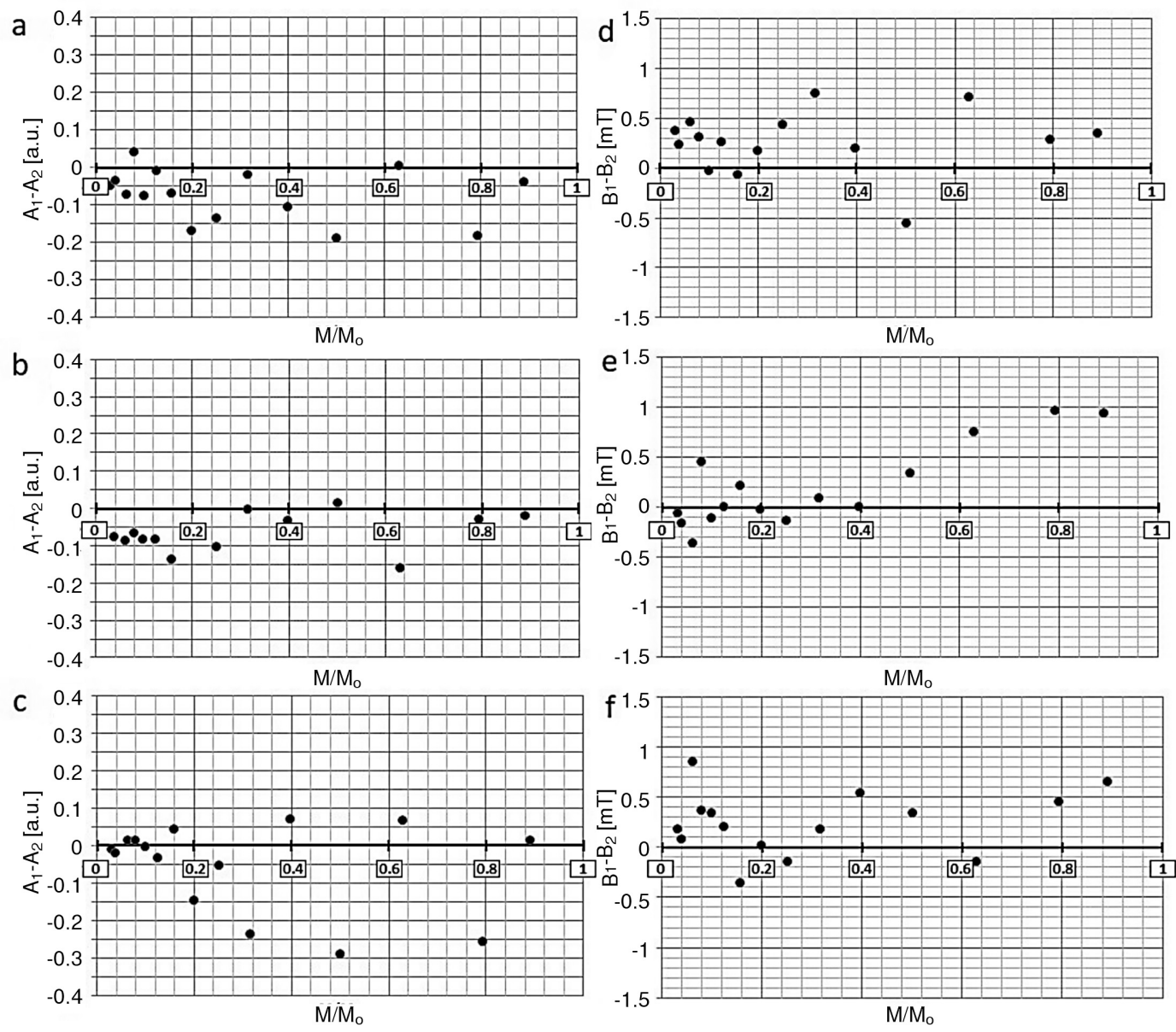

Figure 9. The influence of microwave power $\left(M / M_{0}\right)$ on the shape parameters $A_{1}-A_{2}(a-c)$ and $B_{1}-B_{2}(d-f)$ of the EPR line of salicylic acid heated at temperatures and times: (a, d) $120^{\circ} \mathrm{C}$ and $120 \mathrm{~min},(\mathrm{~b}, \mathrm{e}) 130^{\circ} \mathrm{C}$ and $60 \mathrm{~min}$, and (c, f) $140^{\circ} \mathrm{C}$ and $30 \mathrm{~min} . \mathrm{M}_{\mathrm{o}}, \mathrm{M}-$ the maximal microwave power $(70 \mathrm{~mW})$, and microwave power used during the measurement of the EPR spectra, respectively.

niques and methods. UV-Vis, TGA, colorimetry, and EPR methods were useful, together with microbiological analysis, in optimization of the thermal sterilization process for salicylic acid. The high quality of the sterile product of thermal sterilization according to norms $(5,6,8-11,13)$ was confirmed. The new parameters of thermal sterilization, resulted in the low formation of free radicals in salicylic acid, was proposed. The other parameters, because of high free radical production, were rejected.

\section{CONCLUSIONS}

The UV-Vis, TGA, colorimetry and EPR examination of salicylic acid pointed out that:

1) Free radicals $\left(\sim 10^{18} \mathrm{spin} / \mathrm{g}\right)$ were formed during heating of salicylic acid at temperatures (times): $120^{\circ} \mathrm{C}(120 \mathrm{~min}), 130^{\circ} \mathrm{C}(60 \mathrm{~min})$, and $140^{\circ} \mathrm{C}(30$ $\min )$.
2) Thermal sterilization of salicylic acid may be performed at temperatures (times): $120^{\circ} \mathrm{C}(120 \mathrm{~min})$ (norms) and $130^{\circ} \mathrm{C}(60 \mathrm{~min})$ (the new proposed conditions), because of the lowest free radical formation. Sterilization process carried on the new proposed conditions $\left(130^{\circ} \mathrm{C}, 60 \mathrm{~min}\right)$ produced the lowest free radical concentration in heated salicylic acid. UV-Vis, TGA and colorimetry examinations confirmed thermal stability of salicylic acid at the tested sterilization conditions.

3) Temperature $140^{\circ} \mathrm{C}$ and heating time $30 \mathrm{~min}$ were not recommended for thermal sterilization of salicylic acid, because of the highest free radical formation.

4) The influence of microwave power on EPR spectra of heated salicylic acid indicated fast spin-lattice relaxation processes in the samples.

5) Strong dipolar interactions between unpaired electrons of free radicals existed in thermally 
treated salicylic acid, because of their broad EPR lines. The lowest dipolar interactions characterized salicylic acid heated at temperature $130^{\circ} \mathrm{C}$ for $60 \mathrm{~min}$. The strongest dipolar interactions were obtained for salicylic acid heated at temperature $140^{\circ} \mathrm{C}$ for $30 \mathrm{~min}$.

6) EPR spectroscopy, UV-Vis spectrophotometry, thermogravimetry, and color measurements may be used together with microbiological analysis during optimizing thermal sterilization conditions of salicylic acid.

\section{Acknowledgments}

This work was financially supported by the Medical University of Silesia in Katowice, grant number: KNW-1-067/K/9/O. Professor dr hab. Andrzej B. Więckowski is very grateful for the paramagnetic reference - ultramarine.

\section{Conflict of interests}

The authors declare no conflict of interest.

\section{REFERENCES}

1. Swiss Pharmaceutical Socied. Index Nominum: International Drug Directory 20th edition, MedPharm, Germany 2011.

2. Janiec W., Krupińska J.: Pharmacodynamics, PZWL, Warsaw 2009 (in Polish).

3. Kostowski W., Herman Z.: Pharmacology Basics of Pharmacotherapy, PZWL, Warsaw 2004 (in Polish).

4. Janiec J.: Compendium of Pharmacology, PZWL, Warsaw 2015 (in Polish).

5. Jachowicz R.: Recipe Pharmacy, PZWL, Warsaw2015 (in Polish).

6. Krówczyński L., Jachowicz R.: Recipe Pharmacy Exercises, PZWL, Warsaw 2000 (in Polish).

7. Marszał L.: Pharmacy formulation of semisolid drug formulations on the skin, Farmapress, Warsaw 2015 (in Polish).

8. Polish Pharmacopoeia edition X, PTFarm, Warsaw 2014 (in Polish).

9. European Pharmacopoeia edition VIII. European Directorate for the Quality of MedicinesEDQM 2014.

10. The International Pharmacopoeia edition VIII. World Health Organization 2018.

11. WHO good manufacturing practices for sterile pharmaceutical products-annex 6. World Health
Organization, WHO Technical Report Series No. 961 (2011).

12. Janicki S., Fiebig A.: Applied pharmaceutics. PZWL, Warsaw 2008 (in Polish).

13. Samczewska G.: Apothecary 37, 15 (2009).

14. Karlsson A.K., Larrivee-Elkins C., Molin O.: Sterile powders, formulations, and methods for producting the same. United States Patent US7524834 B2 (2007).

15. Ramos P., Pilawa B.: Pharm. Dev. Technol. 23, 1016 (2018).

16. Ramos P., Pilawa B.: Bioinorg. Chem. Appl. 2014, 9 pages (2014).

17. Ramos P., Pilawa B.: Acta Pol. Pharm. 72, 4 (2015).

18. Ramos P., Pieprzyca M., Pilawa B.: Acta Pol. Pharm. 73, 2 (2016).

19. Skowrońska A., Wojciechowski M., Ramos P., Pilawa B., Kruk D.: Acta Phys. Pol. A 121, 2 (2012).

20. Dołowy M., Ramos P., Pilawa B.: Int. J. Photoenergy 2014, 7 pages (2014).

21. Wilczyński S., Pilawa B., Koprowski R., Wróbel Z., Ptaszkiewicz M., et al.: Radiat. Environ. Bioph. 53, 1 (2014).

22. Wilczyński S., Pilawa B., Koprowski R., Wróbel Z., Ptaszkiewicz M., et al.: Eur. J. Pharm. Sci. 45, 3 (2012).

23. Wilczyński S., Lekki J., Kwiatek W., Chodurek E., Pilawa B.: Pol. J. Environ. Stud. 15, 4A (2006).

24. Subert J., Cizmarik J.: Pharmazie 63, 331 (2008).

25. Popa S., Padure M., Jurcau D., Drutau M.: Chem. Bull. "POLITEHNICA" Univ. (Timişoara) 53, 67 (2008).

26. Stankowski J., Hilczer W.: Introduction to Magnetic Resonance Spectroscopy. PWN, Warsaw 2005 (in Polish).

27. Wertz J.E., Bolton J.R.: Electron Spin Resonance: Elementary Theory and Practical Applications. Chapman and Hall, New York, London 1986.

28. Eaton G.R., Eaton S.S., Salikhov K.M.: Foundatio ns of modern EPR. World Scientific, Singapore, New Jersey, London, Hong Kong 1998.

29. Trivedi M.K., Branton A., Trivedi D., Shettigar H., Bairwa K., Jana S.: Nat. Prod. Chem. Res. 3, 5 (2015).

30. Silverstein R.M., Webster F.X., Kiemle D.J.: Spectroscopic methods for identification of organic compounds. PWN, Warsaw 2007 (in Polish). 
31. Salhab H., Naughton D.P., Barker J.: Molecules 25, 932 (2020).

32. Unal B., Durmus Z., Kavas H., Baykal A., Toprak M.S.: Mater. Chem. Phys. 123, 184 (2010).
33. Lindquist E., Yang Y.: J. Chromatogr. A. 1218, 2146 (2011).

34. Krztoń A., Liszka B., Ramos P., Pilawa B.: Eng. Biomat. 12, 89 (2009).

35. Ramos P., Pilawa B., Krztoń A., Liszka B.: Pharm. Anal. Acta. 3, 9 (2012).

(C) 2020 by Polish Pharmaceutical Society. This is an open-access article under the CC BY NC license (c) (i) () (http://creativecommons.org/licenses/by-nc/4.0/). 